\title{
DRUG REPOSITION OF NON-CANCER DRUGS FOR CANCER TREATMENTS THROUGH PHARMACOVIGILANCE APPROACH - REPURPOSING DRUGS IN ONCOLOGY
}

\author{
MRUGANK PARMAR, SHITAL PANCHAL* \\ Department of Pharmacology, Institute of Pharmacy, Nirma University, Ahmedabad, Gujarat, India. Email: Shital.Panchal@nirmauni.ac.in \\ Received: 05 September 2018, Revised and Accepted: 26 October 2018
}

\begin{abstract}
Objective: This study was performed to reposition the existing non-cancer drug therapy for cancer treatment, which had a well-established pharmacologic profile with better efficacy and least toxicity as an antineoplastic agent.

Methods: This study for drug repositioning was performed for the drugs which are in the market since more than a decade and they are approved with their well-established efficacy and safety profile in human being. We have retrieved the source data from the United States Food and Drug Administration Adverse Event Reporting System for the past 13 years covering duration from 2004 to 2016 and analyzed the data using pharmacovigilance approach "a proposed future novel pharmaceutical tool for drug reposition" and signal management activity.
\end{abstract}

Results: Signal management activity was performed for statistical analysis. It was analysed that propranolol, metformin, pioglitazone, dabigatran, and nitroglycerin which are the existing non-cancer drugs, they deserved for their direct/indirect reposition for cancer treatment and anti-neoplastic activity.

Discussion: Further studies retrieving the source data from other regulatory database (e.g. EudraVigilance of the EMA and VigiFlow of the WHO) and post-marketing surveillance study with the same objective may adjuvant our results for the reposition of existing drugs by pharmacovigilance approach.

Keywords: Drug reposition, Antidiabetic therapy, Cardiovascular therapy, Anticancer therapy, Pharmacovigilance.

(C) 2019 The Authors. Published by Innovare Academic Sciences Pvt Ltd. This is an open access article under the CC BY license (http://creativecommons. org/licenses/by/4. 0/) DOI: http://dx.doi.org/10.22159/ajpcr.2019.v12i2.29523

\section{INTRODUCTION}

Drug repositioning is the novel concept to identify the new indications for drugs which are already approved and marketed for the treatment of unintended diseases or are failed at its developmental stage. The traditional approach for drug development takes at least 12-15 years and $\$ 500$ million- $\$ 2$ billion to bring a single pipeline molecule to the market [1]. Lack of efficacy and serious adverse reactions are two major causes, for which a drug fails in Phase II and III clinical trials [2]. Hence, the development of a novel concept which could predict new therapeutic indications holds a great promise to increase the efficiency of blockbuster molecules of any pharmaceutical organization and to improve the drug discovery pathway.

Initiation of drug repositioning for known molecules with wellcharacterized safety and efficacy profiles could help us to identify the new therapeutic indication for unintended disease and its better transition for the respective population. The transition of sildenafil for the treatment of erectile dysfunctions is one of the best examples for drug repositioning. In 1980, Pfizer Inc. had invented sildenafil for the treatment of coronary artery disease which acts through the inhibition of phosphodiesterase type 5. Penile erection for longer duration was identified as one of its sideeffects during the Phase I clinical trials with the patients of hypertension and angina pectoris [3]. Sildenafil was not found so efficacious for the treatment of angina pectoris in few smallscale clinical trials, and later, it has been approved/repositioned in 1998 by the United States Food and Drug Administration (US FDA) for the treatment of erectile dysfunction.

The drug repositioning approach deals with the observations directly in human post-marketing of the drug, so the way of drug transition for the treatment of unintended disease is more effective and feasible. Another reason why drug repositioning may be one of the efficient approach for drug discovery is because post-marketed drugs are already proved for its (a) chemistry, manufacturing, and control profile, (b) well-versed pharmacokinetic and pharmacodynamic profile, and (c) better safety and efficacy profile [4].

\section{METHODS}

\section{Data collection from public database}

Pharmacovigilance safety data were retrieved from the United States FDA Adverse Event Reporting System (AERS) [5] for the past 15 years covering duration from 2004 to 2018-Q1. Medical dictionary for regulatory activities (MedDRA), Version 19.1, was used to decode the relevant MedDRA preferred terms for reported indications and side effects. In our study, we targeted the drugs for repositioning, which are (I) already in use either for diabetes or cardiovascular disease (II) drugs which are approved with legal basis as generic medicines or wellestablished medicines and (III) drugs which are proved/analyzed for their safe and effective use in human (clinical studies) or in animals (pre-clinical studies). A primary target was set to identify a drug, which may have at least direct/indirect therapeutic or prophylactic effect for cancer therapy based on published literatures/research papers for their anticancer/antineoplastic activity. Pharmacodynamic/molecular mechanism of drugs and phenotypic characteristics of reported side effects was compared with "very common" side effects of drugs, which are approved for the treatment of "cancer" or may act as antineoplastic agents.

The study approach includes identifying the new indication of drugs for unintended disease based on their reported side effects. If two drugs for the treatment of different disease are causing similar side effects, then it indicates that there may be a possible correlation in between 
two drugs for some common mechanism of action and target receptor site. In other words, there is a phenotypic correlation between side effect and disease. Cases reported with only non-serious side effects for at least 3 times with the same drug were considered for further analysis to identify a possible positive signal as per the study objective.

\section{Isolation of serious and nonserious adverse drug reaction}

Adverse drug reactions reported with any one or more of the following outcome "death; a life-threatening adverse event; inpatient hospitalization or prolongation of existing hospitalization; and a persistent or significant incapacity or substantial disruption of the ability to conduct normal life functions, a congenital anomaly/birth defect, important medical event terms, or designated medical event term" were considered as serious adverse drug reaction and they were excluded from further analysis to meet the study objective.

Remaining all other adverse drug reactions were considered as nonserious adverse drug reactions, and they were analyzed further to meet the study objective.

Signal management to identify new indication for drug reposition Signal management activity was performed for all the drug-event combination identified with possible positive signals based on their pharmacodynamic/molecular mechanism of drugs and phenotypic characteristic of reported event as nonserious side effects. This activity was included the following steps in sequence;

a. Signal detection: The process of looking for and/or identifying signals using data from published literatures and relevant authenticated source in support of published data.

b. Signal validation (and confirmation): The process of evaluating the data supporting the detected signal to verify that the available documentation contains sufficient evidence demonstrating the existence of a new potentially causal association, or a new aspect of a known association, and therefore justifies further analysis of the signal. This evaluation was done into account the strength of the evidence, the clinical relevance, and the previous awareness of the association.

c. Signal prioritization, analysis, and assessment: The process continuously performed throughout signal management, which was aimed to identify those signals suggesting minimum or negligible safety concern with no potential important patients' or public health impact or which may not significantly affect the risk-benefit balance of the medicinal product, and thus requires urgent attention to meet the objective of this study to analyze them further for unapproved indication based on their reporting frequency and dechallenge/ rechallenge outcome (if reported).

d. Recommendation for further action as applicable, as per the study objective.

\section{Statistical analysis}

Pharmacovigilance guideline [6] on the "use of statistical signal detection methods in the EudraVigilance data analysis system" was used for statistical analysis in this study. This includes quantitative methods to calculate the proportional reporting ratio (PRR) for confirmed signal. Signals calculated with PRR value more than two were only considered as a positive result outcome.

\section{RESULTS}

A total of 4,236,068 individual case safety reports (ICSRs) were reported for the duration from 2004 to 2018-Q1 to the United States FDA AERS by various pharmaceutical organizations, physicians, patients, or different health authorities. Of the total, 45,853 ICSRs were selected in which the patient was on the treatment for either diabetes or cardiovascular disease. Of the selected, 6826 ICSRs were reported with serious side effects, and hence, as per the study objective, they have been excluded from the further analysis. Remaining 39,027 ICSRs were reviewed for their reported drug therapy, medical/familial history, and non-serious side effects.
Most commonly reported non-serious side effects were alopecia $(n=1092)$, hypothermia $(n=853)$, hyperthermia $(n=702)$, white blood cell count increased $(n=698)$, depression $(n=683)$, anxiety $(n=652)$, immunoglobulin increased $(n=638)$, insomnia $(n=621)$, somnolence $(n=601)$, weight decreased $(n=589)$, hallucination $(n=563)$, convulsion $(n=554)$, dry mouth $(n=480)$, muscle spasms $(n=475)$, hyperhidrosis $(n=461)$, mood swings $(n=429)$, blood cholesterol decreased $(n=373)$, euphoric $\operatorname{mood}(n=369)$, and polyuria $(n=341)$.

Comparative analysis of these non-serious side-effects and drugs was performed to understand their phenotypic characteristics and pharmacodynamic/molecular mechanism with respect to very common side effects of drugs approved for the treatment of "cancer" or may act as antineoplastic agents based on published literature. Meta-analysis of published literature and other authenticated sources suggest that the side effects reported with propranolol (hypothermia, decreased appetite, weight decreased, body temperature decreased, and alopecia); metformin (hypothermia, decreased appetite, weight decreased, body temperature decreased, and alopecia); pioglitazone (white blood cell count increased and alopecia); dabigatran (alopecia); and nitroglycerin (least number of side-effects) may have phenotypic and pharmacodynamic/molecular mechanistic correlation with "very common" side effects for the approved anticancer drug therapy or other prophylactic therapy approved for cancer treatment. An exhaustive review of published literature regarding clinical studies in various scientific databases (Embase, Medline, and PubMed) also supports this analysis for anticancer activity of propranolol, metformin, pioglitazone, dabigatran, and nitroglycerin. Summary of these literatures is presented in the discussion part of this article. Table 1 summarizes the proposed drugs for reposition as an anticancer therapy based on its pharmacodynamic/molecular mechanism of action and reported nonserious side effects.

\section{Statistical analysis}

Signal management activity was performed, supporting the confirmation of proposed drugs reposition for anticancer activity as discussed in Table 1 . We used the most frequent approaches of signal detection methods for calculation of the PRR [24] for the drugs and their reported non-serious events, which was calculated as summarized in Table 2. For all the proposed drug reposition (propranolol, metformin, pioglitazone, and dabigatran), statistical analysis resulted in PRR $>2$ as positive outcomes. Hence, as per the guidance [6] "use of statistical signal detection methods in the EudraVigilance data analysis system," all the proposed drugs may be considered for successful reposition through other confirmative pivotal clinical trial in future. Nitroglycerin has been proposed for reposition based on its pharmacological mechanism for anticancer activity, and it was not assessed through signal management activity due to least number of reported side effects.

\section{DISCUSSION}

Pharmacovigilance analysis aims to search for previously unknown patterns and automatically detect important signals, i.e. drug-associated beneficial effect, from such a large database [25]. In this study, based on the commonly reported non-serious side effects of drugs used in diabetic and cardiovascular disease, we proposed new therapeutic indication for propranolol, metformin, pioglitazone, dabigatran, and nitroglycerin for the treatment of cancer.

There are different innovative methods for new drug development. It takes more than a decade for novel molecules to commercialize them into market. Post-marketing, there are only few molecules $(<5 \%)$ [26] have been proved for its safe and effective use in human being. It would be a great help for health-care and pharmaceutical industries if researcher and scientist could reposition their blockbuster molecules for a new indication in a cost-effective manner. Drug reposition using pharmacovigilance data as a tool is one of the cost-effective and most impactive methods for future drug development. Outsourcing trend has been increased nowadays for different pharmaceutical activities. 


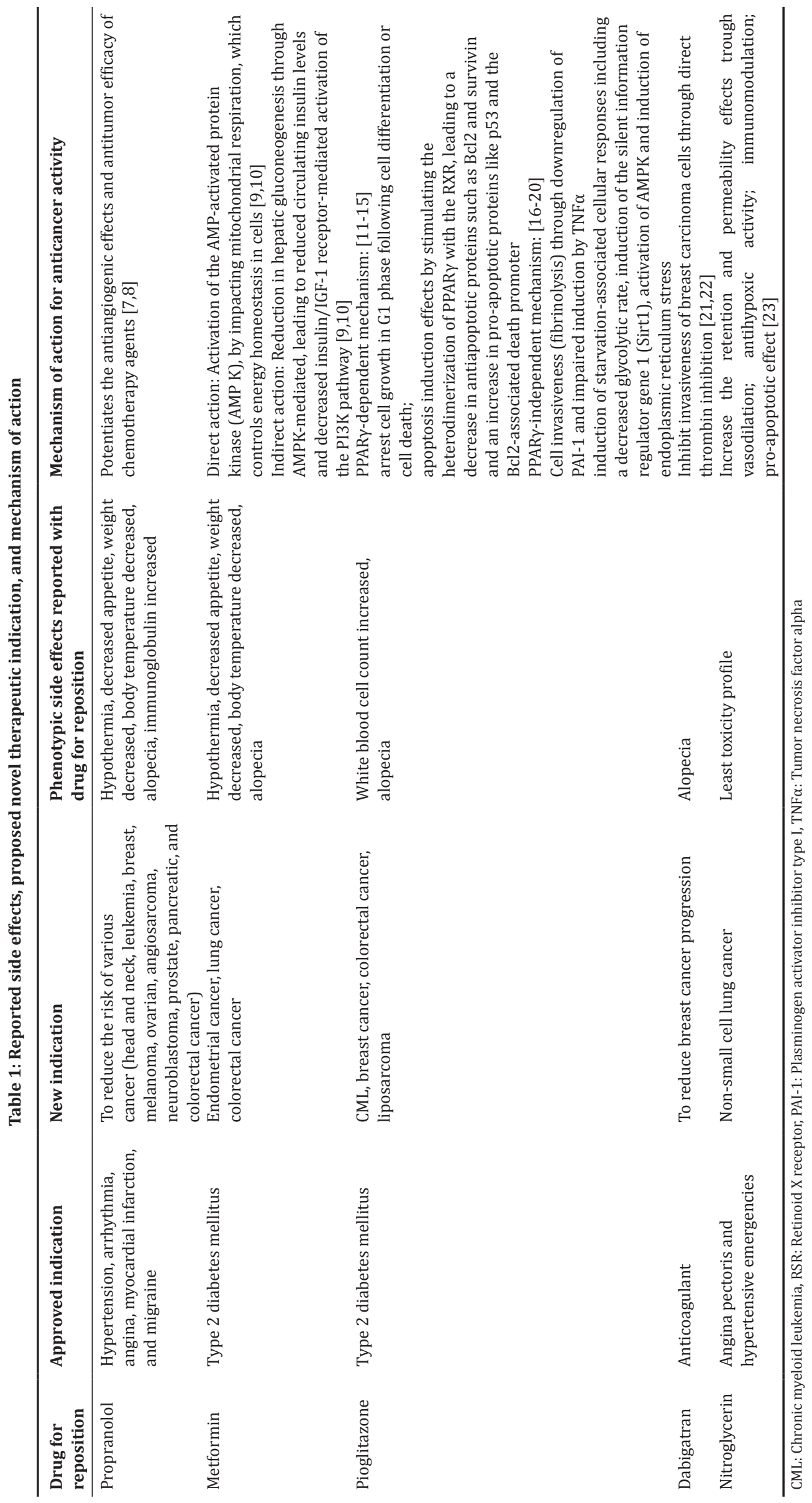


Table 2: Statistical signal analysis

\begin{tabular}{|c|c|c|c|c|c|c|c|}
\hline \multirow{3}{*}{$\begin{array}{l}\text { Proposed drug for } \\
\text { reposition }\end{array}$} & \multicolumn{3}{|c|}{ Reported events with the proposed drug for reposition } & \multicolumn{3}{|c|}{ Other medicinal products } & \multirow[t]{3}{*}{ PRR } \\
\hline & $\begin{array}{l}\text { Non-serious events selected } \\
\text { for anticancer activity }\end{array}$ & $\begin{array}{l}\text { Other } \\
\text { events }\end{array}$ & $A+B$ & $\begin{array}{l}\text { Non-serious } \\
\text { events }\end{array}$ & $\begin{array}{l}\text { Other } \\
\text { events }\end{array}$ & $\mathrm{C}+\mathrm{D}$ & \\
\hline & $\mathbf{A}$ & B & & $\mathbf{C}$ & D & & \\
\hline Propranolol & 596 & 2.302 & 2.898 & 4.952 & 70.771 & 75.723 & 3.14 \\
\hline Metformin & 758 & 2.415 & 3.173 & 5.262 & 70.884 & 76.146 & 3.46 \\
\hline Pioglitazone & 652 & 2.618 & 3.270 & 3.521 & 71.087 & 73.387 & 4.16 \\
\hline Dabigatran & 408 & 2568 & 2976 & 2156 & 52.464 & 54.620 & 3.47 \\
\hline
\end{tabular}

A: Number of individual cases with the suspect medicinal product P involving an adverse event R, B: Number of individual cases related to the suspect medicinal product $\mathrm{P}$, involving any other adverse event except $\mathrm{R}, \mathrm{C}$ : Number of individual cases involving event $\mathrm{R}$ in relation to any other medicinal products but $\mathrm{P}$, D: Number of individual cases involving any other adverse events except $R$ and any other medicinal products except $P$. $P R R=[A /(A+B)) /(C /(C+D)]$

Identification of new indication for well-established molecules through drug reposition technique is one of the innovative outsourcing activities among all. Drug reposition has shown the ability to reduce the risk, time, and cost for drug development.

Clinical study conducted in the past showed that metformin lowers the risk of cancer and has more advantage in cancer with diabetic patient as compared to the patient who has not received metformin therapy along with conventional chemotherapy [27-31]. In one of the preclinical studies, it was concluded by author that metformin together with Vitamin D3 has more impressive result for the prevention of colorectal cancer [32].

A pilot study in chronic myeloid leukemic (CML) patients in chronic residual disease shows that, in spite of continuous treatment with imatinib, when pioglitazone was given temporarily to CML patients, all of them achieved sustained complete molecular response, up to 4.7 years after the withdrawal of pioglitazone [33]. A recent pilot study suggests that pioglitazone may have a preventive effect in colorectal cancer through an effect on aberrant crypt foci and it also has good safety profile in human being [34]. Recent studies have also suggested that pioglitazone has an inhibitory effect on neoplastic cell growth [35-37] and it also induces apoptosis in glandular carcinomas [38,39].

Propranolol decreases the risk of cancer. A large cohort study published for propranolol showed that the overall risk of cancer was lower in the propranolol group and site-specific analysis showed a decreased risk in breast, colon, esophagus, stomach, head and neck cancers, and prostate cancers [40,41]. Propranolol is the choice of drug among all cardiovascular drugs, which may provide safe and effective solutions to cancer. Generic form of propranolol is available globally and is also on the WHO list of essential medicines [8]

A pre-clinical study result showed that oral administration of dabigatran inhibits invasion and metastasis of breast tumors both [21]. Dabigatran gets metabolized through esterase enzyme, independent of cytochrome P-450. It is less susceptible to polymorphism and druginteraction; hence, it is a choice of anticoagulant drug among all in cancer patient $[21,22]$.

Past clinical study showed a positive result for the treatment of lung cancer with nitroglycerin. The result showed that, instead of the treatment for lung cancer with carboplatin and docetaxel alone, response rate was higher (up to $58 \%$ ) after 2 years when nitroglycerin was added to the treatment. Normal expected response rate with chemotherapy is $25-35 \%$ [42]. Treatment with nitroglycerin transdermal patch has showed the better result along with conventional chemotherapy with ease of application on skin and decrease the dose for administration of tablet or intravenous chemotherapy [23].

Thus, the drugs we have analysed in this study, reported positive characteristic for drug reposition, for the treatment of cancer with or without other conventional chemotherapy. These drugs are available in market since long with well-known safety and efficacy profile, good toxicity profile, noncytotoxic, plausible indirect antiangiogenic mechanism to block the tumor target pathway or surrounding microenvironment, synergistic effect, and supportive clinical data in human.

\section{CONCLUSION}

In this article, we showed a power of large human data available through AERS data collection tool, which may ease the path for drug reposition. We showed the power of method we propose for drug reposition, which may not be feasible with the study of compound chemical structure. Although there is less awareness for drug-repositioning through pharmacovigilance method in research industry, nowadays, innovator pharmaceutical organizations have started to establish a separate indication discovery unit for long-term benefit in terms of patent retention for their new chemical entity. On platform-based analysis, these organizations have successfully launched their multiple approved molecules for unintended indications through a path of drugrepositioning and they have got the health regulatory approvals with a minimum cost of development for an orphan disease. This method may enhance the fiscal growth of the organization globally and could help to keep their intellectual property rights with minimum investment.

Evidently, continuous research on drug reposition through other large database may indeed provide a better treatment option for non-curative or an orphan disease.

\section{ACKNOWLEDGMENTS}

We wish to acknowledge the Institute of Pharmacy, Nirma University, located at Ahmedabad, Gujarat, India, for offering us all the required setups to complete this investigation.

\section{FUNDING}

This research did not receive any specific grant from funding agencies in the public, commercial, or not-for-profit sectors.

\section{AUTHORS' CONTRIBUTIONS}

All the authors have contributed equally.

\section{CONFLICTS OF INTEREST}

All authors have none to declare.

\section{REFERENCES}

1. Adams CP, Brantner VV. Estimating the cost of new drug development: Is it really 802 million dollars? Health Aff (Millwood) 2006;25:420-8.

2. Hopkins AL. Network pharmacology: The next paradigm in drug discovery. Nat Chem Biol 2008;4:682-90

3. Boolell M, Allen MJ, Ballard SA, Gepi-Attee S, Muirhead GJ, Naylor AM, et al. Sildenafil: An orally active type 5 cyclic GMPspecific phosphodiesterase inhibitor for the treatment of penile erectile dysfunction. Int J Impot Res 1996;8:47-52.

4. Tobinick EL. The value of drug repositioning in the current pharmaceutical market. Drug News Perspect 2009;22:119-25. 
5. FDA Drug Safety Communication. FDA Requires Removal of Some Prescribing and Dispensing Restrictions For Rosiglitazone-Containing Diabetes Medicines. Available from: http://www.fda.gov/Drugs/ DrugSafety/ucm376389.htm. [Last accessed on 2015 Dec 16].

6. Eudra Vigilance Expert Working Group. The Use of Statistical Signal Detection Methods in the Eudra Vigilance Data Analysis System London; 2006.

7. Pasquier E, Street J, Pouchy C, Carre M, Gifford AJ, Murray J, et al. B-blockers increase response to chemotherapy via direct antitumour and anti-angiogenic mechanisms in neuroblastoma. $\mathrm{Br} \mathrm{J}$ Cancer 2013;108:2485-94

8. Pantziarka P, Bouche G, Sukhatme V, Meheus L, Rooman I, Sukhatme VP, et al. Repurposing drugs in oncology (ReDO)-propranolol as an anti-cancer agent. Ecancermedicalscience 2016;10:680.

9. Leone A, Di Gennaro E, Bruzzese F, Avallone A, Budillon A. New perspective for an old antidiabetic drug: Metformin as anticancer agent. Cancer Treat Res 2014;159:355-76.

10. Nevadunsky NS, Van Arsdale A, Strickler HD, Moadel A, Kaur G, Frimer M, et al. Metformin use and endometrial cancer survival. Gynecol Oncol 2014;132:236-40.

11. Galli A, Mello T, Ceni E, Surrenti E, Surrenti C. The potential of antidiabetic thiazolidinediones for anticancer therapy. Expert Opin Investig Drugs 2006;15:1039-49.

12. Ceni E, Mello T, Tarocchi M, Crabb DW, Caldini A, Invernizzi P, et al. Antidiabetic thiazolidinediones induce ductal differentiation but not apoptosis in pancreatic cancer cells. World J Gastroenterol 2005;11:1122-30.

13. Tontonoz P, Singer S, Forman BM, Sarraf P, Fletcher JA, Fletcher CD, et al. Terminal differentiation of human liposarcoma cells induced by ligands for peroxisome proliferator-activated receptor gamma and the retinoid X receptor. Proc Natl Acad Sci U S A 1997;94:237-41.

14. Elstner E, Müller C, Koshizuka K, Williamson EA, Park D, Asou H, et al. Ligands for peroxisome proliferator-activated receptorgamma and retinoic acid receptor inhibit growth and induce apoptosis of human breast cancer cells in vitro and in BNX mice. Proc Natl Acad Sci U S A 1998;95:8806-11.

15. Kim S, Lee JJ, Heo DS. PPAR gamma ligands induce growth inhibition and apoptosis through p63 and p73 in hum an ovarian cancer cells. Biochem Biophys Res Comm 2011;406:389-95.

16. Weng JR, Chen CY, Pinzone JJ, Ringel MD, Chen CS. Beyond peroxisome proliferator-activated receptor gamma signaling: The multi-facets of the antitumor effect of thiazolidinediones. Endocr Relat Cancer 2006; 13:401-13

17. Galli A, Ceni E, Crabb DW, Mello T, Salzano R, Grappone C, et al. Antidiabetic thiazolidinediones inhibit invasiveness of pancreatic cancer cells via PPARgamma independent mechanisms. Gut 2004;53:1688-97.

18. Liu J, Lu H, Huang R, Lin D, Wu X, Lin Q, et al. Peroxisome proliferator activated receptor-gamma ligands induced cell growth inhibition and its influence on matrix metalloproteinase activity in human myeloid leukemia cells. Cancer Chemother Pharmacol 2005;56:400-8.

19. Omar HA, Salama SA, Arafa el-SA, Weng JR. Antitumor effects of energy restriction-mimetic agents: Thiazolidinediones. Biol Chem 2013;394:865-70.

20. Wei O, Kulp K, Chen S. Energy restriction as an antitumor target of thiazolidinediones. J Biol Chem 2010;285:9780-91

21. DeFeo K, Hayes C, Chernick M, Ryn JV, Gilmour SK. Use of dabigatran etexilate to reduce breast cancer progression. Cancer Biol Ther 2010;10:1001-8.

22. Lal I, Dittus K, Holmes CE. Platelets, coagulation and fibrinolysis in breast cancer progression. Breast Cancer Res 2013;15:207.

23. Sukhatme V, Bouche G, Meheus L, Sukhatme VP, Pantziarka P. Repurposing drugs in oncology (ReDO)-nitroglycerin as an anti-cancer agent. Ecancermedicalscience 2015;9:568

24. Shah G, Patel M, Jat D. Safety signal detection of cardiac disorders adverse drug events for azithromycin in pediatric population using health Canada adverse event reporting system database. Int J Pharm Pharm Sci 2017;9:80-4.

25. Singhal S, Chakraborty B. Evaluation of signal detection for platinum compounds in Canadian spontaneous adverse event reports. Int J Pharm Pharm Sci 2015;7:405-11.

26. Gilbert J, Henske P, Singh A. Rebuilding big pharma's business model. In Vivo 2003;21:73-80.

27. Evans JM, Donnelly LA, Emslie-Smith AM, Alessi DR, Morris AD. Metformin and reduced risk of cancer in diabetic patients. BMJ 2005;1330:1304-5

28. Currie CJ, Poole CD, Jenkins-Jones S, Gale EA, Johnson JA, Morgan CL, et al. Mortality after incident cancer in people with and without Type 2 diabetes: Impact of metformin on survival. Diabetes Care 2012;35:299-304

29. Lega IC, Austin PC, Gruneir A, Goodwin PJ, Rochon PA, Lipscombe LL, et al. Association between metformin therapy and mortality after breast cancer: A population-based study. Diabetes Care 2013;36:3018-26.

30. Landman GW, Kleefstra N, van Hateren KJ, Groenier KH, Gans RO, Bilo HJ. Metformin associated with lower cancer mortality in Type 2 diabetes: ZODIAC-16. Diabetes Care 2010;33:322-6.

31. Eikawa S, Nishida M, Mizukami S, YamazakiC, Nakayama E, Udono H. Immune-mediated antitumor effect by Type 2 diabetes drug, metformin. PNAS 2015;112:1809-14.

32. Li W, Wang QL, Liu X et al. Combined use of vitamin D3 and metformin exhibits synergistic chemopreventive effects on colorectal neoplasia in rats and mice. Cancer Prev Res (Phila) 2015 Feb;8(2):139-48.

33. Prost S, Relouzat F, Spentchian M, Ouzegdouh Y, Saliba J, Massonnet G, et al. Erosion of the chronic myeloid leukaemia stem cell pool by PPAR $\gamma$ agonists. Nature 2015;525:380-3.

34. Takahashi H, Hosono K, Uchiyama T, Sugiyama M, Sakai E, Endo H, et al. PPARgamma ligand as a promising candidate for colorectal cancer chemoprevention: A Pilot study. PPAR Res 2010;2010:257835.

35. Niho N, Takahashi M, Shoji Y, Takeuchi Y, Matsubara S, Sugimura T, et al. Dose-dependent suppression of hyperlipidemia and intestinal polyp formation in min mice by pioglitazone, a PPAR gamma ligand. Cancer Sci 2003;94:960-4.

36. Shimada T, Kojima K, Yoshiura K, Hiraishi H, Terano A. Characteristics of the peroxisome proliferator activated receptor gamma (PPARgamma) ligand induced apoptosis in colon cancer cells. Gut 2002;50:658-64.

37. Shen D, Deng C, Zhang M. Peroxisome proliferator-activated receptor gamma agonists inhibit the proliferation and invasion of human colon cancer cells. Postgrad Med J 2007;83:414-9.

38. Rumi MA, Sato H, Ishihara S, Ortega C, Kadowaki Y, Kinoshita Y, et al. Growth inhibition of esophageal squamous carcinoma cells by peroxisome proliferator-activated receptor-gamma ligands. J Lab Clin Med 2002;140:17-26.

39. Eibl G, Wente MN, Reber HA, Hines OJ. Peroxisome proliferatoractivated receptor gamma induces pancreatic cancer cell apoptosis. Biochem Biophys Res Commun 2001;287:522-9.

40. Chang PY, Huang WY, Lin CL, Huang TC, Wu YY, Chen JH, et al. Propranolol reduces cancer risk: A Population-based cohort study. Medicine (Baltimore) 2015;94:e1097.

41. Barron TI, Connolly RM, Sharp L, Bennett K, Visvanathan K. Beta blockers and breast cancer mortality: A population- based study. J Clin Oncol 2011;29:2635-44.

42. Yasuda H, Nakayama K, Watanabe M, Suzuki S, Fuji H, Okinaga S, et al. Nitroglycerin treatment may enhance chemosensitivity to docetaxel and carboplatin in patients with lung adenocarcinoma. Clin Cancer Res 2006;12:6748-57. 